\title{
Simulation of intercepting bus stations in a major city
}

\author{
Alena Antipova, and Olga Smirnova* \\ Industrial University of Tyumen, 620000, 38, Volodarskogo st., Tyumen, Russia
}

\begin{abstract}
The article discusses the experience of developing and testing a methodology for studying the movement of buses on scheduled routes in intercity and suburban traffic from the bus terminal of a major city. The AnyLogic 8 University simulation package was used for visual representation of traffic, which allows us to get quantitative characteristics of traffic on an hourly schedule as a result. Based on the results of the study, a logistics approach was developed to determine the location of transport hubs "bus terminal/bus station", as a system of intercepting bus stations that should be integrated into the route network of the major city.
\end{abstract}

\section{Introduction}

Transport communications in the major city play a large social role in public service. The route network, due to the rapid development of regional centers, does not meet the needs of most passengers. Suburban, intercity and international buses that enter from country roads and go to the city center to the bus station also create an additional load on traffic on the city's road network. The urban road network of major cities is characterized by dense intersections, narrow roadways, two-level interchanges, heavy traffic, and peak loads, which complicates the movement of large comfortable and/or articulated buses and leads to an increase in traffic time on the route in the city. In metropolitan cities, this problem is complicated by the presence of several bus stations, which are usually located in the city center, and the movement of the bus from the bus station to the exit to the federal road takes 40 minutes or more. The problem of determination of the optimal location of the bus station lies at the junction of two scientific directions - urban planning and transport. Most of the research related to bus stations as passenger transport hubs was carried out by architects and urban planners, which relate to the layout and internal organization of work $[1,2,3]$.

The authors propose to develop a methodology for studying the order of bus traffic in the "As - is" format, since it is necessary to know from which side the buses approach the city, the volume and size of such traffic. In addition, it is necessary to take into account the presence of other types of public transport (ground, underground), the status of the airport and railway station. So, the airport of the city of Yekaterinburg "Koltsovo" is the largest interregional center where the residents of such cities as Kurgan, Tyumen and Chelyabinsk go. A number of trains go through the Kurgan railway station to other countries and the Caucasus, bypassing the city of Yekaterinburg. Tyumen residents take a bus to Kurgan. In this regard, the issue of determining the location of intercepting bus stations in the major

\footnotetext{
*Corresponding author: smirnovaoj@tyuiu.ru
} 
city should be approached comprehensively, taking into account interregional passenger flows, requirements for major transport hubs (TIH) and types of urban route network.

\section{Methods of research of the order of movement of international, intercity and suburban communication buses}

The analysis of bus traffic should begin with studying the geographical map of the regional and/or regional center where federal, regional, and local highways are mapped. Having determined all existing exits from the city to federal, regional, and municipal highways, it is necessary to obtain quantitative characteristics of passenger traffic (the number of buses and passengers transported), or as they call it on railway transport "traffic size". These indicators are determined in two directions (exit from the bus station on the city's road network to the highways and entry from the highways on the city's road network in the direction of the bus terminal(s)), simultaneously recording on the geographical map of the city the point of departure and the route along the road network before (or since the moment) leaving the city. The information data array at this stage is collected from official documents that are publicly available online on the official websites of transport agencies: the Register of international bus routes, the Register of interregional regular transport routes, the Register of intermunicipal regular transport routes, the Register of local stations.

Further, information is updated according to the current schedule, preferably in two ways: winter and summer with details by day of the week. Additionally, information is added about the transportation of passengers on seasonal routes in suburban traffic that do not go to the bus stations (dacha, garden). All traffic size indicators obtained are distributed in the directions of departure from the city. Knowing the number of regular-routes, the type of rolling stock, the daily schedule of buses and their route on the city's road network, the construction of a model of bus traffic in the "As is" format was performed. The diagram of the process of studying the movement of international, intercity and suburban buses with access to the identification of potential locations of intercepting bus stations in the IDEF0 notation is shown in figure 1. After conducting analytical research and interviewing experts, the location of four intercepting bus stations in the city of Tyumen was proposed: TIH Patrushevo Bus Station, TIH Plekhanovo Bus Station, TIH a/k1228 Bus Station, and TIH Andreevsky Bus Station. Names are selected based on the slang name of urban districts. The results of traffic modeling in the city of Tyumen in the "As is" format are presented in work [4].

\section{Logistics approach to the determination of the system of intercepting bus stations}

Based on the results of research on the order of bus traffic on the street network of the city of Tyumen (Russia), it should be noted that local planning methods are incorrect. In this regard, it is necessary to combine the optimization of the route network of different types of communication and different types of transport both in the region and in the city (bus, tram, trolleybus, subway) [5]. The use of logistics principles (integration, integrity and consistency) in the construction of a system of intercepting bus stations will compensate for the uncertainty of some environmental factors [6,7]. Optimizing the city route network in the city, one should begin by identifying suburban and intercity flows that go from different directions to the city, both by rail and by road transport. The bus route network is a little easier to change than the tram and trolleybus network. The farthest final stops from the city center should be marked, getting a closed loop. Further, taking into account the general plan of city development (settlement and development plan), the geographical location the 
remaining transport hubs in the city and promising ones should be noted. These include railway stations, airports, existing bus stations, and other local transport hubs. At a separate stage, the issue of regional routes reforming with the transfer to rail transport is being considered, synchronizing the schedule of passengers' transportation to suburban railway stations, which may lead to the cancellation of some intercity bus routes.

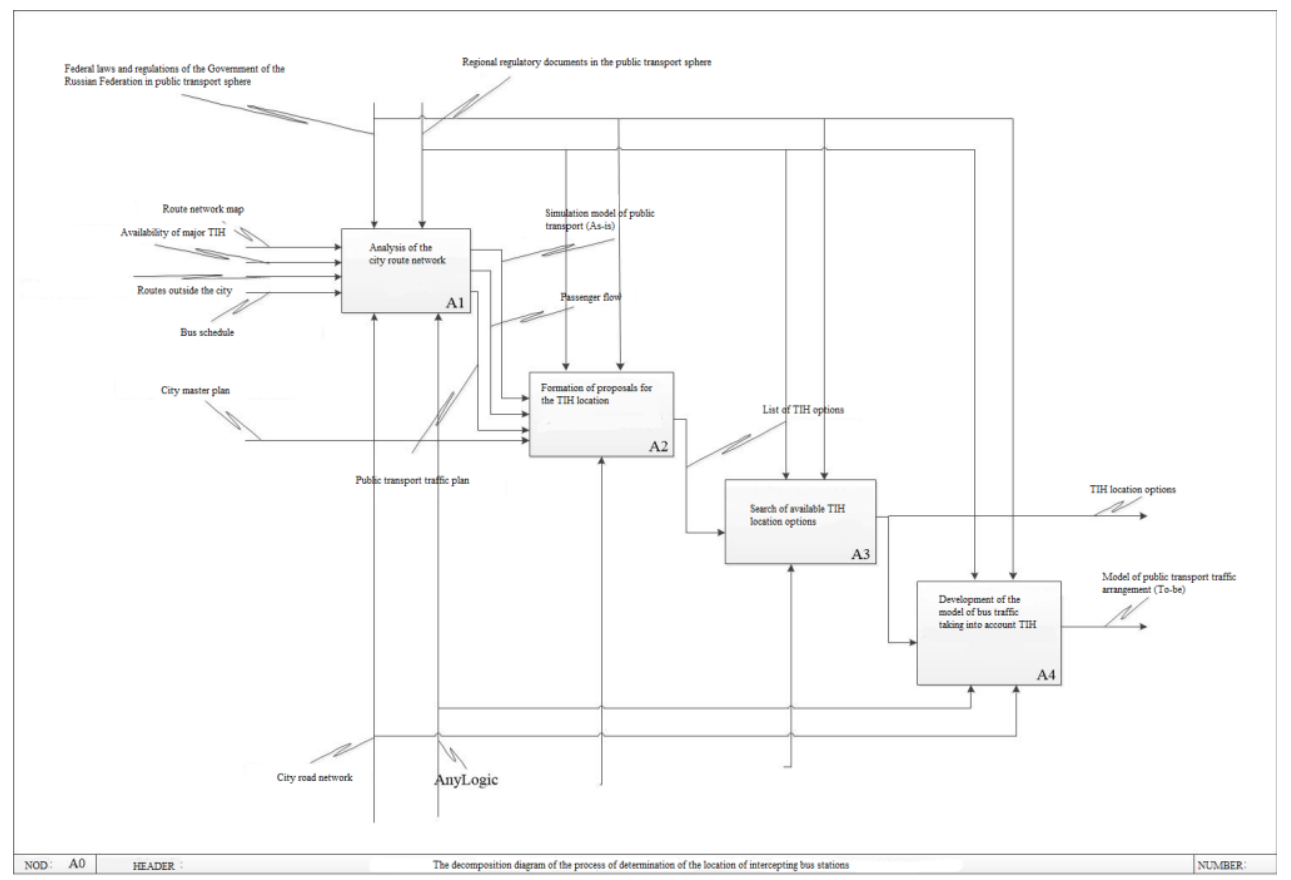

Fig. 1. IDEF0 Diagram of the international, intercity and suburban bus traffic research process.

After the simulation procedures, a consultation is held with the specialists of the bus station and other experts on the choice of the location of the TIH Bus Station (intercepting) at the entrances to the city. At the same time, having studied the question of the availability of free and/or abandoned land plots for the construction of such TIH, it should also be noted that it is incorrect to break off the route schemes within the borders of the region. It is proposed to take into account stable passenger flows in inter-regional traffic. This stage of adjustment requires consideration at the federal level. In practice, it is not easy to solve the issues of inter-municipal and inter-regional integration because of the division of powers between executive bodies.

After completing the approval procedures, several options are determined for placing intercepting bus stations to organize the transfer of passenger traffic from other cities and suburbs to urban transport, taking into account the availability of free from development or abandoned land plots. The final stage is to make a decision on the location of the intercepting bus station. The procedure for selecting such TIH is developed in sufficient detail by the authors Vlasov D., Nemov P. [8,9].

Based on the results of the work, a model for organizing public transport traffic in several variants, taking into account intercepting stations, has been developed. It is an integrated information medium that combines all the necessary information resources of 
road transport enterprises (Fig.2). The main core of the model is a data storage that includes the following types of information:

- routes timetables;

- registers of regional, intermunicipal, and municipal regular transport routes;

- register of local stations;

- maps of highways and the city road network;

- data from the city master plan.

The advantage of such storage is that it is constantly updated to quickly track all changes in the transport situation in the major city. The algorithm embedded in the model and shown in Figure 3 will allow to automatically rebuild the scheme of intercepting stations, for example, when entering new cottage settlements, planning an additional transport ring, or restructuring the route network of the city [10].

From an economic point of view, this model does not require financial investments and with a high-quality pre-project analysis, it is able to flexibly respond to all environmental factors that have a significant impact on the efficiency of transport services for the population of the major city.

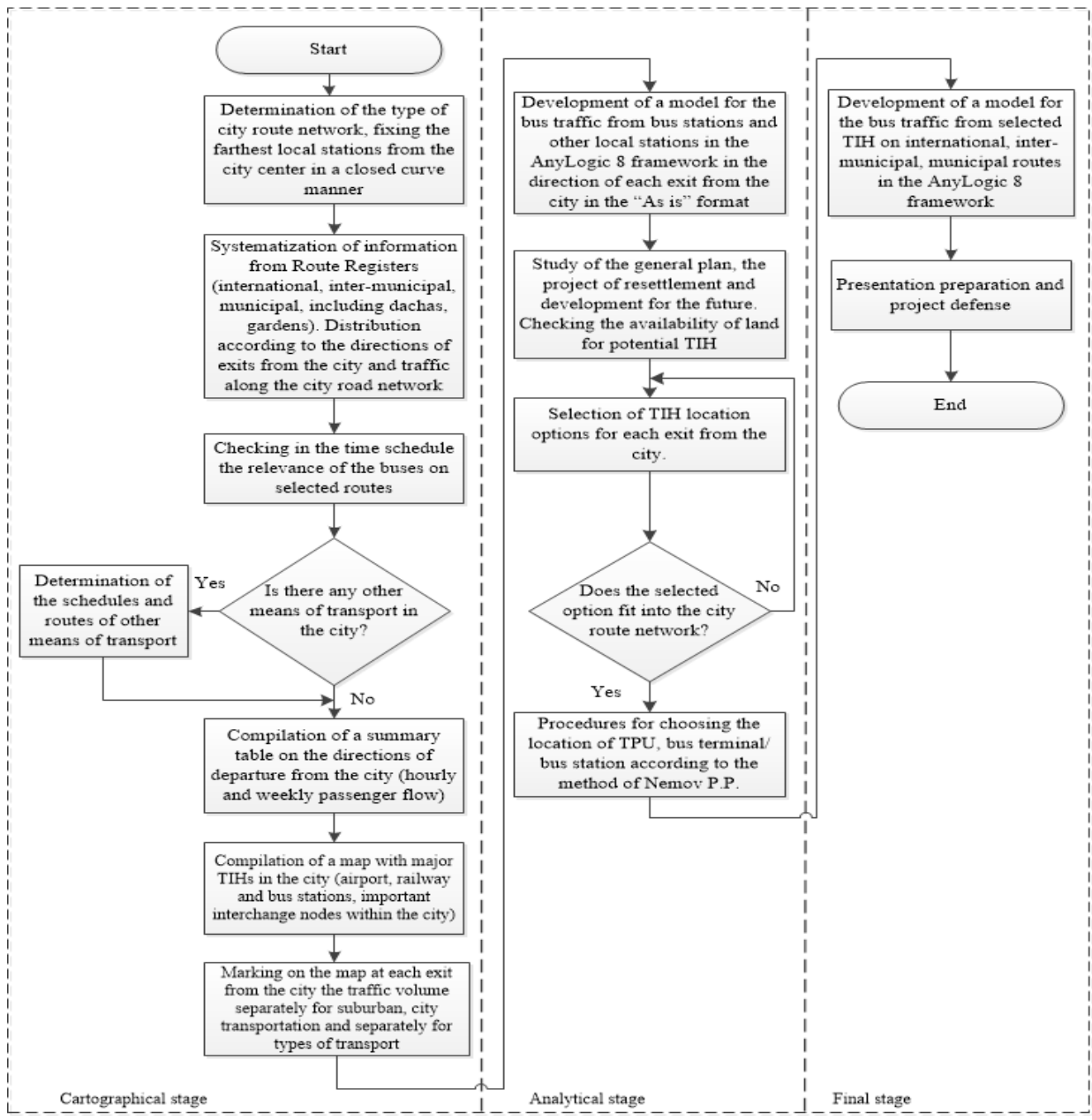

Fig. 2. Algorithm of the logistics approach to the construction of intercepting bus stations system. 


\section{Conclusions}

Thus, based on the results of the work, the methodology for studying the order of movement of international, intercity and suburban buses along the city road network from (to) bus stations has been developed. Analytical information is formed from traffic schedules, registers of regional, intermunicipal and municipal routes of regular transport, register of local stations, maps of highways and the city road network, taking into account the movement of buses on suburban, country-garden routes.

The AnyLogic 8 University (educational version) simulation package was used for visual representation of traffic, which allows us to get quantitative characteristics of traffic on an hourly schedule as a result. As a result, a model of public transport (excluding urban transport) in the "As is" format was obtained.

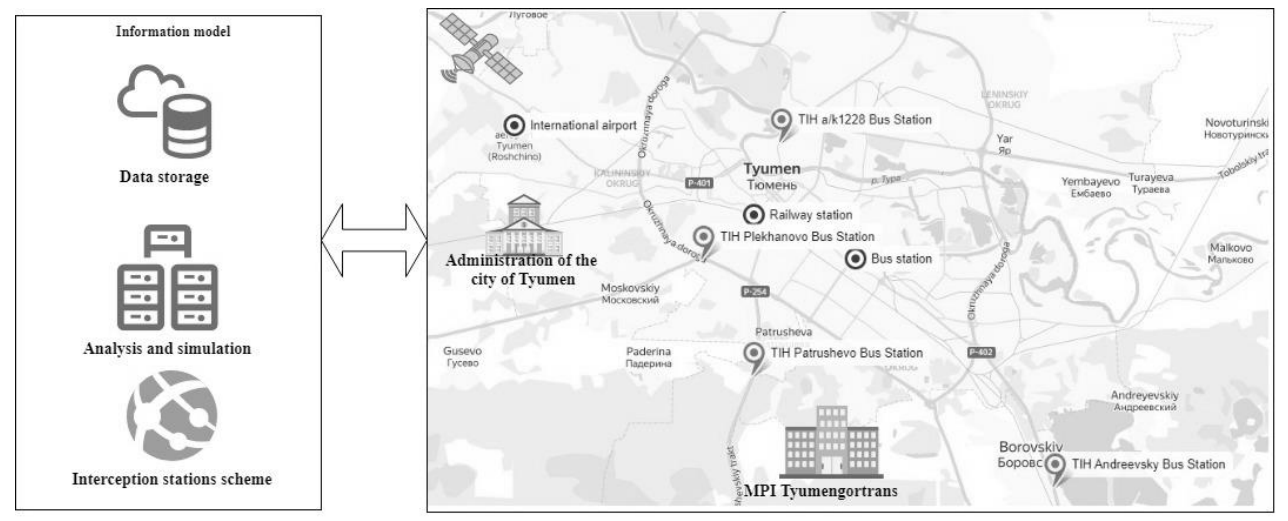

Fig. 3. Information model of forming transport interchange hubs (intercepting bus stations)

In the future, the introduction of additional functional modules in mobile applications already available in a number of cities is considered that allow tracking the movement of public transport, in order to inform citizens about the work of intercepting bus stations in a timely manner.

Upon completion of work, a logistics approach was developed to determine the location of transport hubs "bus terminal/bus station", as a system of intercepting bus stations that should be integrated into the route network of the major city.

\section{References}

1. W. Wang, H. Yi. Advances in Intelligent Systems Research, 30, 1084 (2016)

2. S. Dzidic, L. Snegar, Proc. of 7th International Conference "Contemporary Achievements in Civil Engineering", 811 (2019)

3. S. Dzidic, L. Snegar, Proc. of 12th Scien. Conf. on Production Engineering, RIM 2019, 2566-3283, 268 (2019)

4. Evstratova, O. Smirnova, Proc. of 3th Int. Scien. Conf. Transport planning and modeling. Digital future of transport management, 139 (2018)

5. Alexander Y. Ryzkov, Pavel V. Zyuzin, Urban Public Transport Development in Russia: Trends and Reforms (Springer, Cham, 2016)

6. L. Mochalova, O. Sokolova, V. Yurak, Journal of Environmental Management and Tourism, 10 (1), 202 (2019)

7. Goryainov, A. Grudnitskaya, Eastern-European journal of enterprise technologies, 3(34), 51 (2008)

8. D. Vlasov, P. Nemov, The Bulletin of BSTU named after V.G. Shukhov, 3, 61 (2018) 
9. P. Nemov, The Eurasian Scientific Journal, 10 (3), 59 (2018)

10. A. Baublys, Computer Modelling and New Technologies, 6 (1), $72-81$ (2002) 